\title{
Assessment of parasitic load in goat through the examination of faecal matter
}

\author{
Rajesh Kumar $^{1 *}$, B.P. Singh ${ }^{2}$ and S.S. Patil ${ }^{3}$ \\ ${ }^{1}$ Department of Veterinary Extension, Veterinary College, JAU, Junagadh-362001 (Gujarat), INDIA \\ ${ }^{2}$ Division of Extension Education, ICAR- IVRI, Izatnagar-243122, Bareilly (Uttar Pradesh), INDIA \\ ${ }^{3}$ Department of Animal Nutrition, Veterinary College, JAU, Junagadh-362001 (Gujarat), INDIA \\ *Corresponding author's E-mail: rajeshvet30@gmail.com
}

\section{ARTICLE HISTORY}

Received: 17 August 2017

Revised received: 07 September 2017

Accepted: 06 October 2017

\section{Keywords}

Faecal matter

Gastrointestinal nematodes

Grazing ruminants

Goat

McMaster technique

Parasitic load

\begin{abstract}
Parasitic infection do not show heavy rate of mortality, however there occurrence being chronic, most of the time leads to serious production losses, this led to study about severity of parasitic load and type of parasitic infection in goats. Parasitic infection most of the time leads to serious production losses. Gastrointestinal nematodes are ubiquitous parasites of grazing ruminants and cause decreases in survival, live weight gain, wool and milk production and reproduction performance. Parasitic problems are a serious problem in goat. Total 60 goat faecal samples were analyzed. These results would serve as a baseline for future studies. The majority of the faecal samples $(70 \%)$ of both zone I and zone II had heavy parasitic load (>3000 epg) followed by 60 per cent samples of zone III. This indicates that majority of the goats of the study area had severe parasitic infection. Chi-square analysis revealed non-significant relation between parasitic load and categories of zones. Majority of samples ( $48.33 \%$ ) were infected with the combination of Strongyles, Strongyloides and Coccidiosis. It can be concluded that faecal egg count level was severe in majority of the samples examined.
\end{abstract}

(C2017 Agriculture and Environmental Science Academy

Citation of this article: Kumar Rajesh, Singh, B.P. and Patil, S.S. (2017). Assessment of parasitic load in goat through the examination of faecal matter. Archives of Agriculture and Environmental Science, 2(4): 315-317, DOI: 10.26832/24566632.2017.020412

\section{INTRODUCTION}

Livestock sector plays an important and vital role in providing nutritive food and in supplementing family incomes and generating gainful employment in the rural sector, particularly among the landless, small and marginal farmers. India with 135 million goat population stands second after China. Goats are generally reared by landless or the resource poor farmers whose average agricultural holding is either very less or is not sufficient to devote for cultivation of crops (Kumar and Pant, 2003 and Singh et al., 2005). Goat sector provides subsidiary source of livelihood to the people especially to small and marginal farmers and landless labourers. Technological and management options are the only alternatives to accelerate growth in the productivity of goats, which is low in the traditional system of production.

Parasites are a major constraint on animal productivity throughout the world. Small ruminant (goats and sheep) production systems worldwide are significantly constrained by gastrointestinal nematode (GIN) parasites, reducing meat, milk, and fibre production (Preston et al., 2014). Epidemiological studies are necessary to determine the potential impact of parasitic infections in particular areas (Chaparro et. al., 2016). Gastrointestinal nematodes are ubiquitous parasites of grazing ruminants and cause decreases in survival, live weight gain, wool and milk production and reproduction performance. These losses can be particularly severe in developing countries where control measures are less readily available.
Correlation between faecal egg count of trichostrongylid eggs and worm burden, making faecal egg count a good estimate for affected animals (Rodriguez et al., 2015). Gastrointestinal parasitic infections in small ruminants are of considerable economic importance because small ruminants' rearing has been a major source of income especially to the marginal farmers and labours of the country. Parasitic problems are a serious problem in goat. Parasitic infection do not show heavy rate of mortality, however there occurrence being chronic, most of the time leads to serious production losses. This leads to the major problem that goat farm produce below capacity. Keeping above point in view the study was planned to access the parasitic load and type of parasite infects the goats.

\section{MATERIALS AND METHODS}

To assess the parasitic worm load in goat through faecal sample examination, two districts were selected from each of the three agro-climatic zone on the basis of highest density of goat population. From each selected district, two blocks were randomly selected. Thus from each each zone four blocks were selected and from each block five faecal samples were collected randomly. From each zone 20 samples were analyzed. Total 60 faecal samples were analyzed. Result of the study presented in frequency, percentage etc. The McMaster technique was used for counting helminth eggs in faecal samples. Two grams of faeces were weighed with a scale with 0.1 gram incitement, thereafter; $28 \mathrm{~mL}$ of saturated sodium 
chloride $(\mathrm{NaCl})$ solution was added. The faecal solution was then run through a strainer after it had been soaked for 5 minutes, and immediately filled a McMaster chamber with a plastic pipette. The McMaster chamber was then let to stand for at least 5 minutes so the eggs would be able to float to the surface before trichostrongylid eggs were counted in a microscope run by light at $100 \mathrm{X}$ magnification. The number of trichostrongylid eggs per gram (EPG) faeces was calculated by multiplying the total number of trichostrongylid eggs found in the two chambers by a factor of 50 meaning that each trichostrongylid egg found in the McMaster chamber represents 50 eggs per gram faeces (Zajac and Conboy, 2012). It provided information with regard to severity of infection. Faecal sample were taken directly from the rectum with the help of index finger to avoid contamination. When it was difficult to take rectal sample, then fresh faeces were collected from the field or floor. Only top of the faecal lump, untouched with earth was lifted. Identification of nematode eggs has been made on the basis of morphological characteristics features. The obtained result categorized into three categories viz., mild, moderate and severe infection.

\section{RESULTS AND DISCUSSION}

Heavy infections can lead to acute clinical diseases and eventually to mortalities. Many species of nematodes, cestodes and coccidia cause parasitic gastritis and enteritis in goats. Trematode infections lead to damages of the liver. Expenses for treatment and prevention are a massive burden in animal husbandry (Sharma et al., 2011). Faecal examination of sample revealed heavy parasitic load in the study area. The majority of the faecal samples $(70 \%)$ of both zone I and zone II had heavy parasitic load (>3000 epg) followed by 60 per cent samples of zone III. This indicates that majority of the goats of the study area had severe parasitic infection. Moderate infection (1000-3000 epg) was reported in 25 per cent samples from both zone II and zone III followed by 20 per cent samples of zone I while mild infection was found only in 5 per cent samples of zone II followed by 15 per cent samples of zone III and 10 per cent samples of zone I mentioned in table 1. Result of overall collected samples also indicates that majority of the samples had severe parasitic load followed by moderate to mild parasitic load. Results are in line with the study conducted by Suchita et al. (2010) in Patna district of Bihar. She reported in her study that parasitic fauna of goats were as $H$. contortus $(89.76 \%), T$. colubriformis $(84.81 \%), S$. papillosus (62.04\%), Strongyles $(53.13 \%)$ and $T$. ovis (12.21\%). M. expansa (3.96\%) was the common cestode, while ova of trematodes viz., Paramphistomes (33.99\%) and Fasciola spp. (12.87\%) were also detected in faecal samples of goats. The prevalence of Haemonchus sp., Oesophagostomum sp., Trichuris sp., Trichostrongylus sp. was $61.11 \%$, $45.56 \%, 30.00 \%$ and $11.11 \%$, respectively and the mixed infection (57.78\%) was reported by Molla and Bandyopadhyay (2013). Lkhagvatseren et al. also (2015) reported a prevalence of $91.6 \%$ small ruminants infected with Haemonchus spp. The average daily gain in severely affected kids was much lower than moderately affected kids (Sharma et al., 2011). Chi-square analysis was performed to find association between parasitic load and categories of zones. The results revealed non-significant relation between parasitic load and categories of zones. Table 2 shows that majority of samples $(48.33 \%)$ were infected with the combination of Strongyles, Strongyloides and Coccidiosis followed by 33.33 per cent samples infected with both Strongyles and Coccidiosis, 13.33 per cent samples with only Coccidiosis and 5 per cent with both Strongyloides and Coccidiosis.

Table 1. Parasitic load in faecal sample of goats.

\begin{tabular}{|c|c|c|c|c|c|}
\hline Parasitic load (epg) & Zone I (n=20) & Zone II $(\mathrm{n}=\mathbf{2 0})$ & Zone III $(\mathrm{n}=\mathbf{2 0})$ & Overall $(\mathrm{N}=60)$ & Pearson Chi-Square \\
\hline Mild infection (up to 1000) & $2(10.00)$ & $1(5.00)$ & $3(15.00)$ & $\begin{array}{c}10 \\
(10.00)\end{array}$ & 0.513 \\
\hline Moderate infection (1000-3000) & $4(20.00)$ & $5(25.00)$ & $5(25.00)$ & $14(23.33)$ & \\
\hline Severe infection $(>3000)$ & $14(70.00)$ & $14(70.00)$ & $12(60.00)$ & $40(66.67)$ & \\
\hline
\end{tabular}

Table 2. Parasitic distribution of faecal sample of goat.

\begin{tabular}{lcc}
\hline \multicolumn{1}{c}{ Infection of parasite } & Number of sample infected & Percentage \\
\hline Only Strongyles & 0 & 0.00 \\
Only Strongyloides & 0 & 0.00 \\
Only Coccidiosis & 8 & 13.33 \\
Strongyles and Strongyloides & 0 & 0.00 \\
Strongyles and Coccidiosis & 20 & 33.33 \\
Strongyloides and Coccidiosis & 3 & 5.00 \\
Strongyles, Strongyloides and Coccidiosis & 29 & 48.33 \\
\hline
\end{tabular}

\section{Conclusions}

It can be concluded that faecal egg count level was severe in majority of the samples examined. Most prevalent parasitic combination was Strongyles, Strongyloides and Coccidiosis in infected samples. Only Strongyles infected samples were not reported in the study.
Open Access: This is open access article distributed under the terms of the Creative Commons Attribution License, which permits unrestricted use, distribution, and reproduction in any medium, provided the original author(s) and the source are credited. 


\section{REFERENCES}

Chaparro, J.J., Ramírez, N.F., Villar, D., Fernandez, J.A., Londono, J., Arbelaez, C., Lopez, L., Aristizabal, M., Badel, J., Palacio, L.G. and Olivera, M. (2016). Survey of gastrointestinal parasites, liver flukes and lungworm in feces from dairy cattle in the high tropics of Antioquia, Colombia. Parasite Epidemiology and Control, 1(2): 124-130.

Kumar, S. and Pant, K.P. (2003). Development perspectives of goat rearing in India: Status, issues and strategies. Indian Journal of Agricultural Economics, 58(4): 752-767.

Lkhagvatseren, S., Bayarmaa, B., Khatanbaatar, I., Battur, T., Battsetseg, G. and Batsukh, Z. (2015). Antihelmintic resistance to gastrointestinal parasites in small ruminants, pasturing in Dundgobi, Mongolia. Proceedings of 21st International Scientific Conference on current issues on zoonotic diseases, Mongolia, 2015. pp 45-51.

Molla, S.H. and Bandyopadhyay, P.K. (2016). Prevalence of gastrointestinal parasites in economically important Bonpala sheep in India. Journal of Agriculture and Veterinary Science, 9(1): 87-93.

Preston, S.J.M., Sandeman, M., Gonzalez, J. and Piedrafita, D.
(2014). Current status for gastrointestinal nematode diagnosis in small ruminants: Where Are We and Where Are We Going? Journal of Immunology Research. http:// dx.doi.org/10.1155/2014/210350

Rodriguez, A.V., Goldberg, V., Viotti, H. and Ciappesoni, G. (2015). Early detection of Haemonchus contortus infection in sheep using three different faecal occult blood tests. Open Veterinary Journal, 5(2): 90-97.

Sharma, D.K., Mandal, A. and Singh, S.K. (2011). Coccidian infection of Barbari kids: The effect on growth performance. Journal of Veterinary Parasitology, 25(2): 143-145.

Singh, V.K., Suresh, A., Gupta, D.C. and Jakhmola, R.C. (2005). Common property resources of rural livelihood and small ruminants in India: A review. Indian Journal of Animal Science, 75 (8):1027-1036.

Suchita, K., Sinha, S.R.P., Sinha, S., Hoda, M.Z., Mandal, K.G. and Sharma, S.K. (2010). Incidence of gastrointestinal helminthosis in sheep and goats in Patna (Bihar). Journal of Veterinary Parasitology, 24(1): 97-99.

Zajac, A.M. and Conboy, G.A., (2012). Veterinary Clinical Parasitology, 8th Edition. John Wiley \& Sons, Inc., Ames, Iowa, USA. 